The Free Internet Journal

for Organic Chemistry
Account

Arkivoc 2020, part i, 96-116

Organic Chemistry

\title{
Organosilanes in the synthesis of saturated heterocycles
}

\begin{abstract}
Carlos Díez-Poza, Laura Fernández-Peña, Alberto Cherubin, Juan Lión-Villar, and Asunción Barbero*
Department of Organic Chemistry, Faculty of Science, Campus Miguel Delibes, 47011 Valladolid, Spain
\end{abstract}

Email: asuncion.barbero@uva.es

Received 11-15-2019

Accepted 01-09-2020

Published on line $05-04-2020$

\section{Abstract}

This account summarizes the studies towards the synthesis of saturated heterocycles using the chemistry of organosilanes. Two different synthetic approaches are described: a) the acid-mediated cyclization of unsaturated silyl alcohols and b) the silyl-Prins (or silyl-aza-Prins) cyclization of silylated alkenols. The effect of substitution on the selectivity of the annulation process is evaluated.

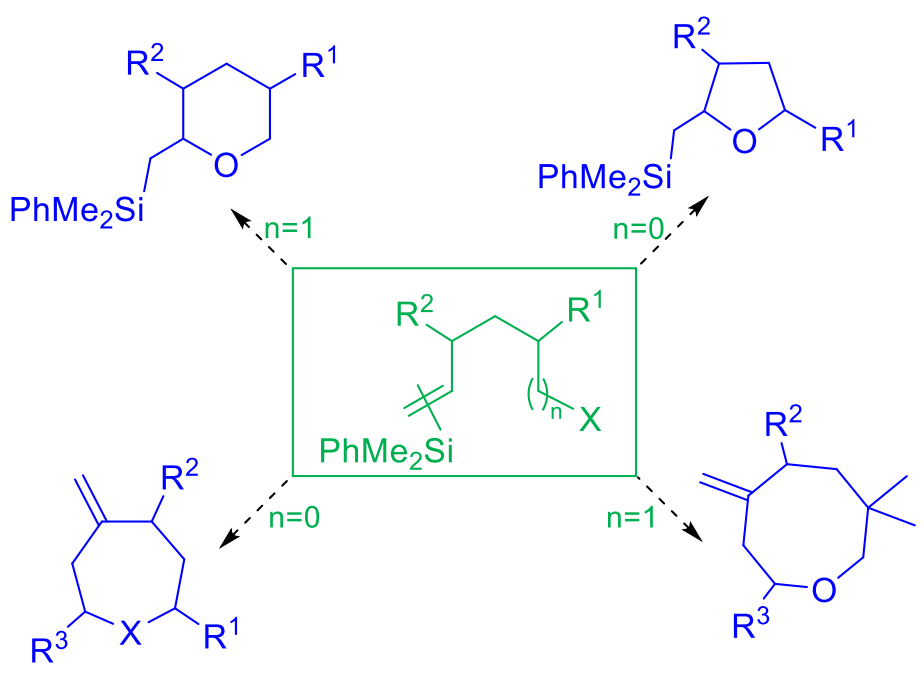

Keywords: Heterocycles, silyl-Prins reaction, cyclization, organosilanes, stereoselection, domino processes 


\section{Table of Contents}

1. Introduction

2. Synthesis of Oxacycles by Electrophilic Cyclization of Silyl Alkenols

2.1 Synthesis of five-membered oxacycles by hydroalkoxylation of allylsilyl alcohols

2.2 Synthesis of five-membered oxacycles by hydroalkoxylation of vinylsilyl alcohols

2.3 Synthesis of six-membered oxacycles by hydroalkoxylation of vinylsilyl alcohols

3. Synthesis of Oxacycles by silyl-Prins Cyclization

3.1 Synthesis of seven-membered oxacycles

3.2 Synthesis of eight-membered oxacycles

4. Synthesis of Azacycles by Silyl-aza-Prins Cyclization

5. Conclusion

6. Acknowledgements

References

\section{Introduction}

Saturated heterocycles are important scaffolds with interesting biological properties, which are present in a wide variety of natural products. For instance, tetrahydrofurans appear in the structures of natural bioactive molecules including squalene-derivatives with cytotoxic activity such as glabrescol, ${ }^{1}$ polyethers isolated from the wood of Spathelia glabrescens, or amphidinolactone $\mathrm{B}^{2}{ }^{2}$ a macrolide isolated from the marine dinoflagellate Amphidinium sp. Moreover, new molecules with this substructure are discovered almost every year, like the recently described leoligin (Figure 1), a lignan isolated from the roots of edelweiss (Leontopodium nivale spp. alpinum) possessing antiinflammatory properties and being a compound relevant for cardiovascular disease. ${ }^{3}$

Of the many natural products containing six-membered oxacycles, 2,2,5-trisubstituted tetrahydropyrans are especially abundant. An example is the natural malyngolide, ${ }^{4}$ an antibiotic extracted from the cyanobacterium Lyngbya majuscula, which shows activity against Mycobacterium smegmatis and Streptococcus pyogenes. Others are the 2,5-disubstituted rhopaloic acids $A$ and $B{ }^{5}$ isolated from a marine sponge Rhopaloeides sp. which exhibit potent inhibitory activity against the embryonic development of the starfish Asterina pectinifera or the recently isolated ecteinamycin (Figure 1), ${ }^{6}$ which has neuroprotective, antibacterial and antimetastatic activities.

Similarly, a plethora of examples of oxepanes can be found in the structures of biologically active compounds. ${ }^{7}$ Among them raspacionin ${ }^{8}$ is a triterpenoid isolated from the marine sponge Raspaciona aculeata, which shows anticancer activity against the MCF-7 tumor cell line. Another example is aplysistatin (Figure 1), ${ }^{9}$ found in algae of the genus Laurencia, which inhibits the progression of murine lymphocytic leukemia P-388 and has antimalarial and antiinflammatory activities. ${ }^{10}$ Last in the series, oxocanes are also present as structural elements in some natural products such as ansellone $\mathrm{B}^{11}$ a sesterterpenoid isolated from a sponge identified as Phorbas sp.

Regarding aza heterocycles, azepanes can be found in molecules like balanol, ${ }^{12}$ a potent PKC inhibitor isolated from Verticillium balanolides, or ophiocordin, ${ }^{13}$ which was isolated from Cordyceps ophioglossoides and has antifungal activity. 


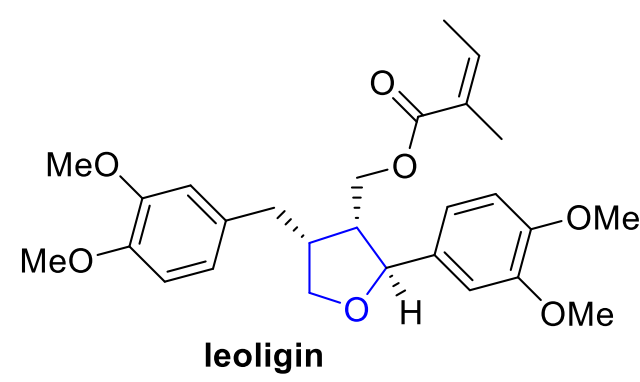

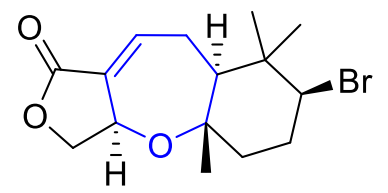

aplysistatin

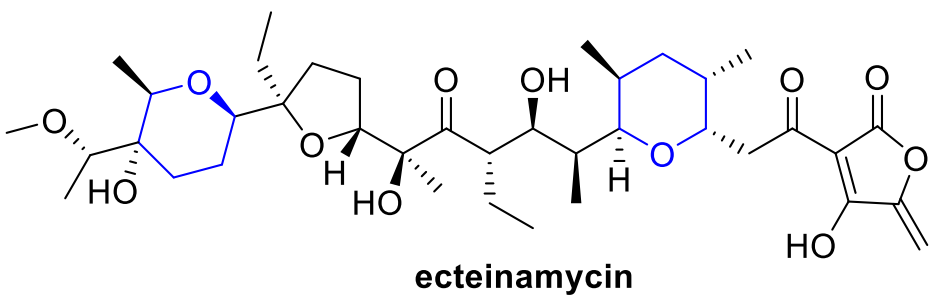

Figure 1

Numerous synthetic approaches have been proposed for the synthesis of these fascinating structures. Among them, the electrophilic cyclization of alkenols and the Prins cyclization have been recognized as some of the most efficient ring-forming reactions.

Our group has long been devoted to the application of organosilicon compounds ${ }^{14}$ to the synthesis of carbo- and heterocycles. ${ }^{15,16}$ In this account, we mainly intend to give an overview of our contributions to the synthesis of different sized heterocycles through these two methodologies.

\section{Synthesis of Oxacycles by Electrophilic Cyclization of Silyl Alkenols}

The electrophilic cyclization of unsaturated alcohols has been found to be an efficient tool for the preparation of different types of cyclic ethers. This procedure usually relies on the use of mercury salts, ${ }^{17}$ halogens ${ }^{18}$ and selenium reagents ${ }^{19}$ to promote the addition to the olefin. However, only few examples have been reported for the corresponding cyclization of alkenols mediated by either Brønsted ${ }^{20,21}$ or Lewis acids, ${ }^{22,23}$ mainly due to associated drawbacks such as side reactions and the lack of generality. ${ }^{24}$

In this framework, we decided to develop a general approach to the synthesis of cyclic ethers of different ring size, focussing on the use of activated alkenyl moieties (such as alkenyl silanes), which may be able to circumvent said limitations of the alkene activation methodology. We expected that the well-known ability of silicon to stabilize carbocations in the $\beta$-position will favour the cyclization. Accordingly, we chose two different groups, allyl and vinyl silanes.

\subsection{Synthesis of five-membered oxacycles by hydroalkoxylation of allylsilyl alcohols}

The starting allylsilyl alcohols required for the study were readily prepared in two steps using self-developed methodology of silylcupration of allene and trapping of the intermediate cuprate with $\alpha, \beta$-unsaturated carbonyl compounds, to produce allylsilyl aldehydes or ketones of general structure 1 . Further reduction with $\mathrm{LiAlH}_{4}$ affords a mixture of the respective allylsilyl alcohols $\mathbf{2}$ and $\mathbf{3}$ in high yields (Scheme 2). ${ }^{25}$ 


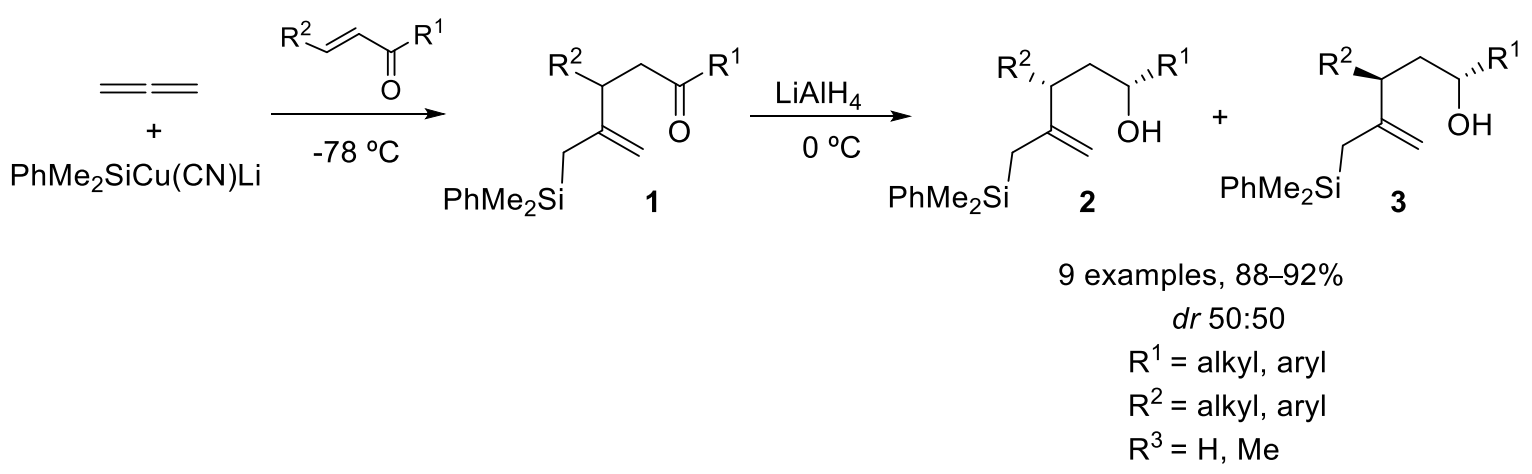

\section{Scheme 2}

The acid-mediated cyclization of these allylsilyl alcohols furnishes the corresponding tetrahydrofurans $\mathbf{4}$ and 5 (Error! Reference source not found.) with both Brønsted (TsOH) and Lewis acid $\left(\mathrm{AlCl}_{3}\right)$, although yields are generally higher in the reaction with Brønsted acids. ${ }^{26}$ The stereoselectivity of the process depends on the substitution pattern of the starting silyl alkenol. Thus, while moderate selectivity ( $d r$ up to 73:27) is obtained with primary alcohols bearing an allylic substituent $\left(R^{2} \neq H ; R^{1}=H\right)$ for the stereoisomer with a 2,3-trans relationship between $R^{2}$ and the silyl group, equimolar mixtures of diastereomers are obtained when using alcohols with $\mathrm{R}^{2}=\mathrm{H}$ and $\mathrm{R}^{1} \neq \mathrm{H}$. The best stereoselectivities are observed for secondary alcohols bearing allylic substituents $\left(R^{1}\right.$ and $\left.R^{2} \neq H\right)$.

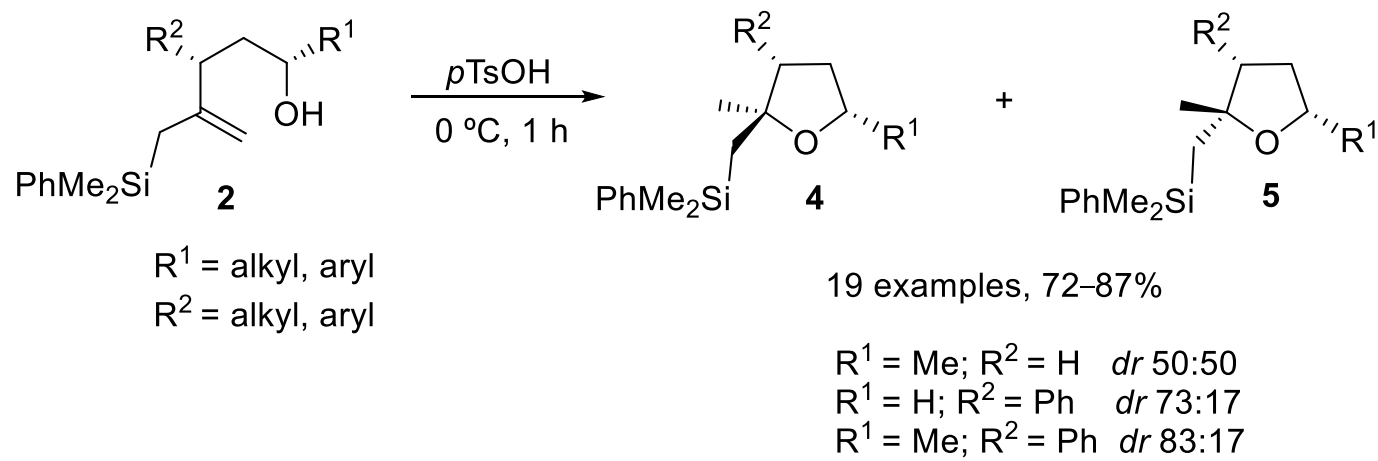

\section{Scheme 2}

A plausible mechanism for this cyclization involves the initial protonation of the hydroxyl group to form an oxonium ion, which in turn delivers the proton to the double bond anti to the silyl group. The corresponding $\beta$-silyl carbocation thus formed (in which the C-Si bond is parallel to the empty $p$ orbital) is then trapped by the nucleophilic hydroxy group opposite to the silyl group. The favorable formation of stereoisomer 4 can be rationalized by studying the two possible reactive conformations (I and II) (Scheme 3). As shown, the unfavorable 1,3-diaxial interaction present in conformation II explains the preferred formation of isomer 4 from conformation I.

An interesting aspect to be studied in this cyclization is the influence of the nature of the silyl moiety in the selectivity of the process. For that purpose, Hosomi ${ }^{27,28}$ and our group chose vinylsilanes as the substrates. 

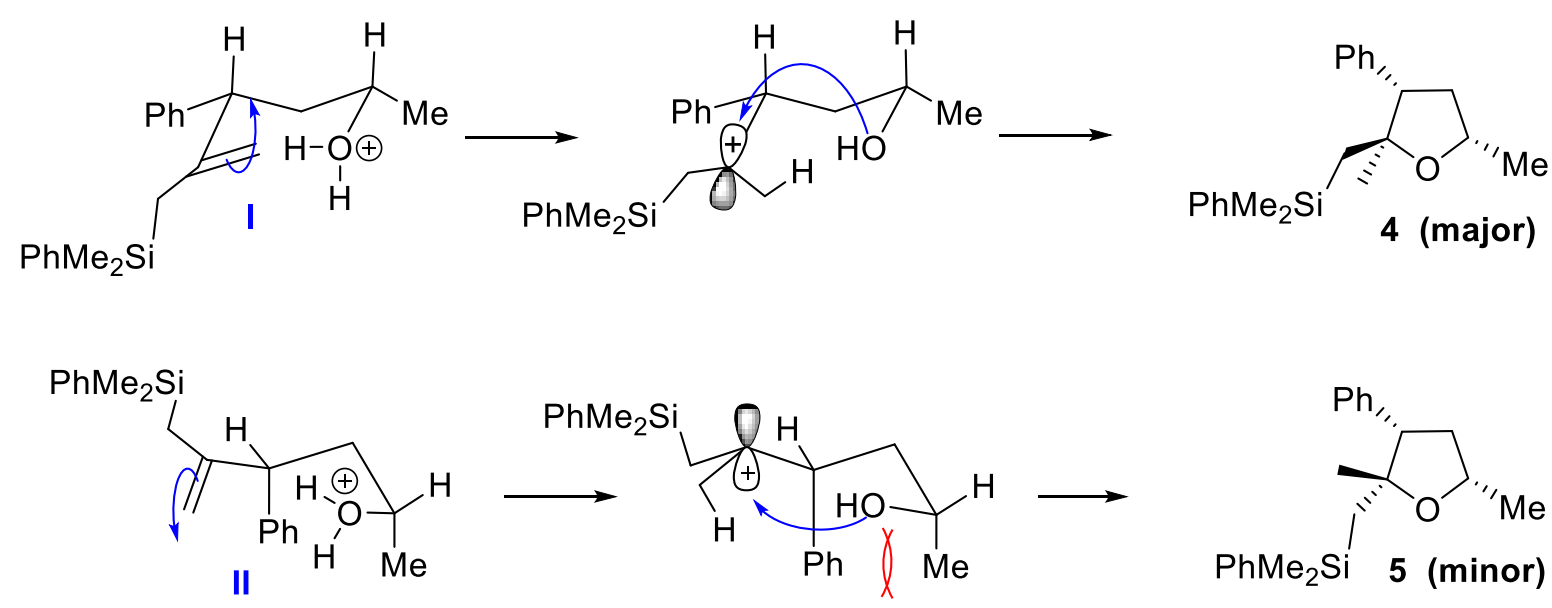

\section{Scheme 3}

\subsection{Synthesis of five-membered oxacycles by hydroalkoxylation of vinylsilyl alcohols}

The use of less reactive nucleophiles, such as vinylsilanes, in the hydroalkoxylation cyclization implies the need of higher temperatures for the reaction to take place. Moreover, the stereoselectivity of the ring forming process is substantially improved when vinylsilyl alcohols are used instead of the allylsilyl derivatives.

A thorough study was performed to evaluate the effect of the substitution pattern of the starting alcohol in the selectivity of the process. ${ }^{29}$ It was found that the presence of an allylic substituent on the vinylsilyl alcohol was essential to obtain total stereocontrol in the cyclization (towards the 2,3-trans-disubstituted tetrahydrofuran). In fact, the ring annulation of secondary alcohols lacking this type of substituents provide only moderate selectivity towards the 2,3-trans-disubstituted stereoisomer. The stereocontrolled preparation of 2,3,5-trisubstituted tetrahydropyrans was easily achieved from alcohols with both $\mathrm{R}^{1}$ and $\mathrm{R}^{2} \neq \mathrm{H}$ (Scheme 4).

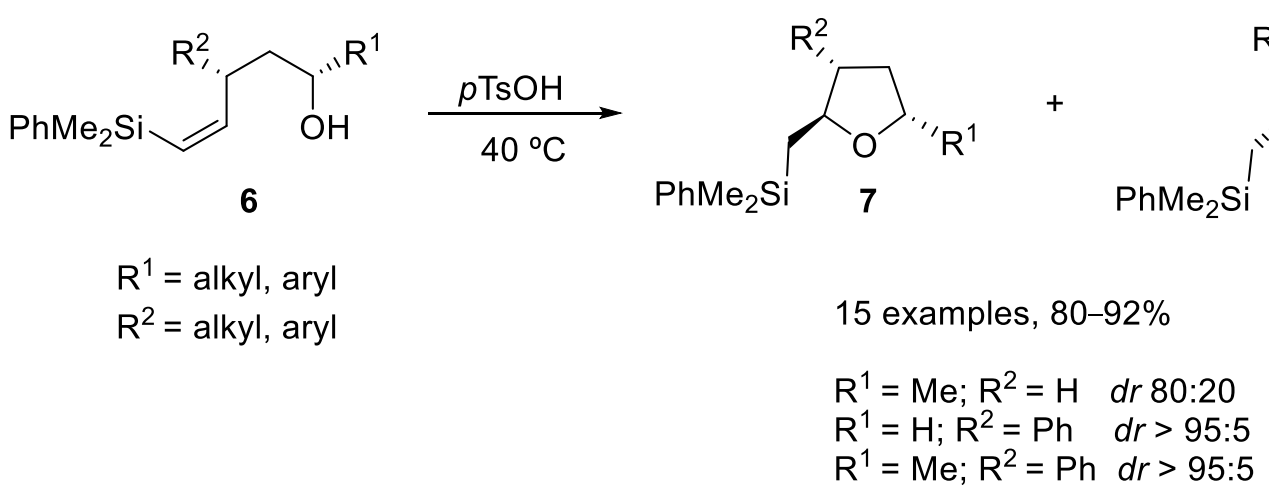

\section{Scheme 4}

Regarding the stereochemical outcome of the cyclization, vinylsilanes (and likewise allylsilanes) always provide the major stereoisomer with a 2,3-trans configuration. On the basis of these experimental results, together with DFT calculations, a preferred reactive conformation (III) has been proposed, which avoids the unfavorable 1,3-allylic interaction shown in the alternative conformation IV. In this case, the cation formed by addition of a proton from the oxonium ion to the double bond (IIIa) undergoes rotation about the C-C bond by the shortest pathway in order to locate the C-Si bond parallel to the empty p orbital (IIIb) (Scheme 5). 


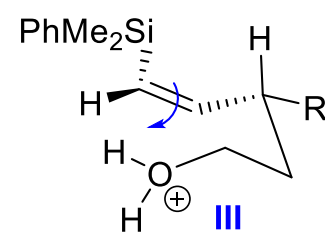
$\mathrm{H}^{\prime}{ }^{\oplus}$ III

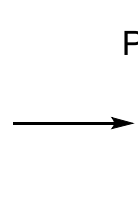

$\longrightarrow \mathrm{PhMe}_{2} \mathrm{Si}$

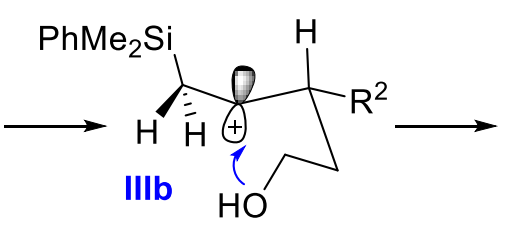

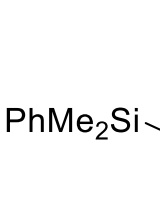

$\mathrm{R}^{2}$<smiles>C1CCOC1</smiles>

Favored<smiles>[R]C1CCO[C@@H]1C[SiH2]OCCN</smiles>

\section{Scheme 5}

Furthermore, the formation of tetrasubstituted tetrahydrofurans was accomplished when vinylsilyl alcohols with $\beta$-substituted vinylsilanes are used (Scheme 6). However, the cyclization of these substrates provides now an almost equimolar mixture of stereoisomers, probably due to competing destabilizing steric effects.

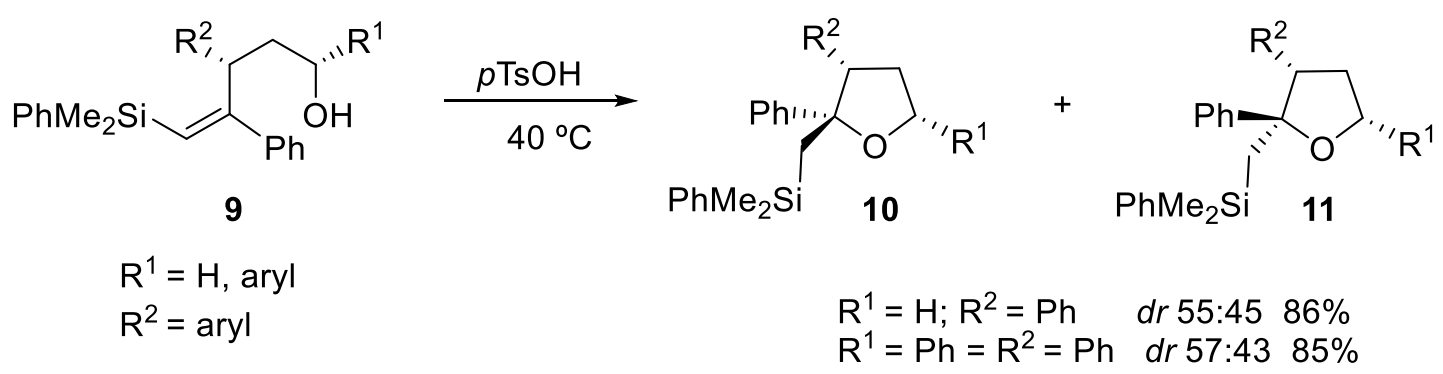

\section{Scheme 6}

\subsection{Synthesis of six-membered oxacycles by hydroalkoxylation of vinylsilyl alcohols}

Due to the scarcity of examples of the synthesis of tetrahydropyrans by acid-mediated cyclization of alkenols, we decided to take an approach using activated silyl alkenols. ${ }^{30}$ Fortunately, the reaction of these electron rich alkenes, in the presence of $p$ - $\mathrm{TsOH}$, furnishes the desired tetrahydropyranyl derivatives in good yields. The reaction is general for various types of substituted silylated alkenols. Moreover, a remarkable stereocontrol is observed in this cyclization, providing a single diastereoisomer in most cases (Scheme 7).

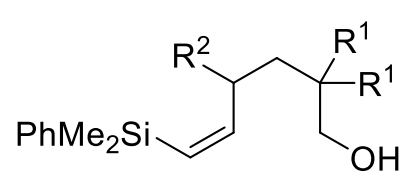

12

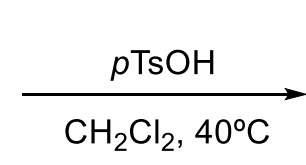

$\mathrm{PhMe}_{2} \mathrm{Si}$

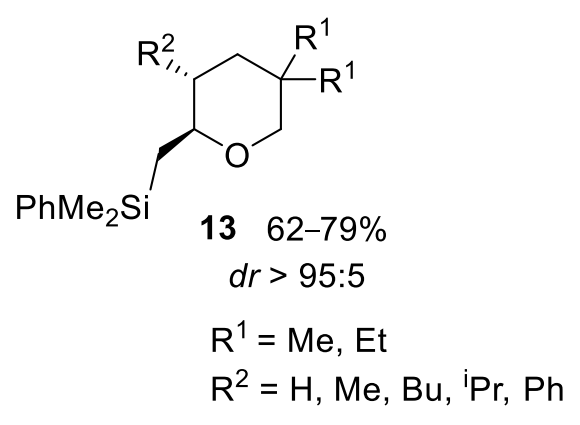

\section{Scheme 7}

An important substituent effect was again observed for $\beta$-substituted vinylsilanes. In this case, the nature of the substituent on the $\beta$-position turned out to play a relevant role, since $\beta$-alkyl-substituted vinylsilanes 
undergo cyclization with excellent stereoselectivity, while decreased stereocontrol was observed when the substituent on the $\beta$-position is an aryl group (Scheme 8 ).

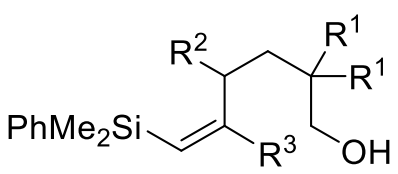

14

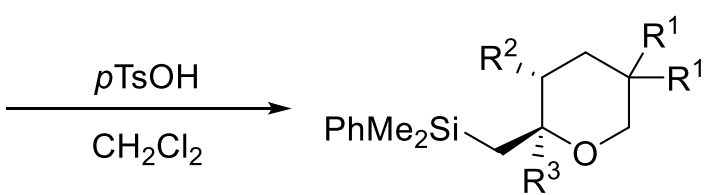

15

10 examples

$\mathrm{R}^{1}=\mathrm{Me} ; \mathrm{R}^{2}=\mathrm{Ph} ; \mathrm{R}^{3}={ }^{\mathrm{n}} \operatorname{Pr} d r>95: 5 \quad 71 \%$

$\mathrm{R}^{1}=\mathrm{Et} ; \mathrm{R}^{2}=\mathrm{Me} ; \mathrm{R}^{3}={ }^{\mathrm{n}} \operatorname{Pr} d r>95: 5 \quad 70 \%$

$\mathrm{R}^{1}=\mathrm{Me} ; \mathrm{R}^{2}=\mathrm{Ph} ; \mathrm{R}^{3}=\mathrm{Ph} \quad d r 79: 21 \quad 65 \%$

$\mathrm{R}^{1}=\mathrm{Me} ; \mathrm{R}^{2}={ }^{\mathrm{i}} \mathrm{Pr} ; \mathrm{R}^{3}=\mathrm{Ph} \quad d r 91: 9 \quad 72 \%$

\section{Scheme 8}

Interestingly, the presence of a remaining silyl group in the oxacycle allows the possibility of further chemical modification, which was used to prepare marine drug analogs. (Scheme 9)

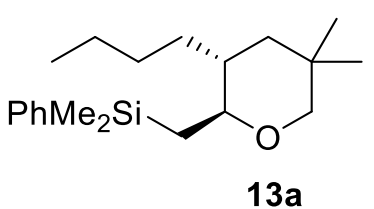

$13 a$

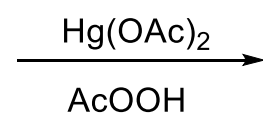

$\mathrm{AcOOH}$

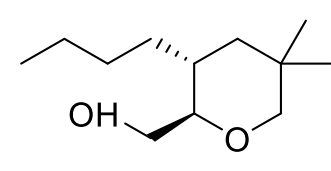

$1660 \%$

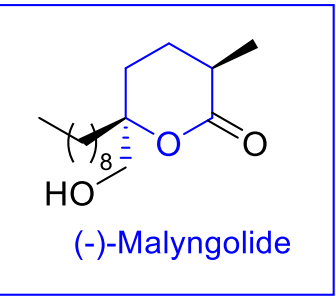

\section{Scheme 9}

\section{Synthesis of Oxacycles by Silyl-Prins Cyclization}

Prins cyclization has proven to be a very efficient and reliable methodology for the construction of cyclic ethers. $^{31,32}$ The general accepted mechanism for this reaction involves the acid-promoted condensation of an alkenol with an aldehyde to provide an oxocarbenium ion, which readily undergoes endo-cyclization. The intermediate cyclic carbocation thus formed is finally trapped by a nucleophile present in the media (frequently provided by the acid). ${ }^{33}$ A variation of the classical Prins cyclization, the silyl-Prins cyclization, has found wide application in heterocyclic chemistry owing to multiple advantages including faster reactions, higher selectivity of the process or lesser side reactions. ${ }^{34}$

In the silyl-Prins cyclization an electron-rich silylated alkenol is used as nucleophile in the process. The overall mechanism is similar to the standard Prins cyclization, except for the fact that the intermediate cyclic carbocation is now a stabilized cation $\beta$ to silicon, which preferably undergoes elimination of the silyl group (and formation of a double bond) rather than by addition of a nucleophile. For instance, this strategy has been used by Keck in the construction of a key intermediate of cytotoxic macrolide dactylolide ${ }^{35}$ (Scheme 30). The high stereoselectivity of this cyclization towards the formation of a single cis-2,6-disubstituted tetrahydropyran $\mathbf{1 7}$ is explained by a preferred chair-like transition state in which all the substituents adopt the minimum energy conformation. 


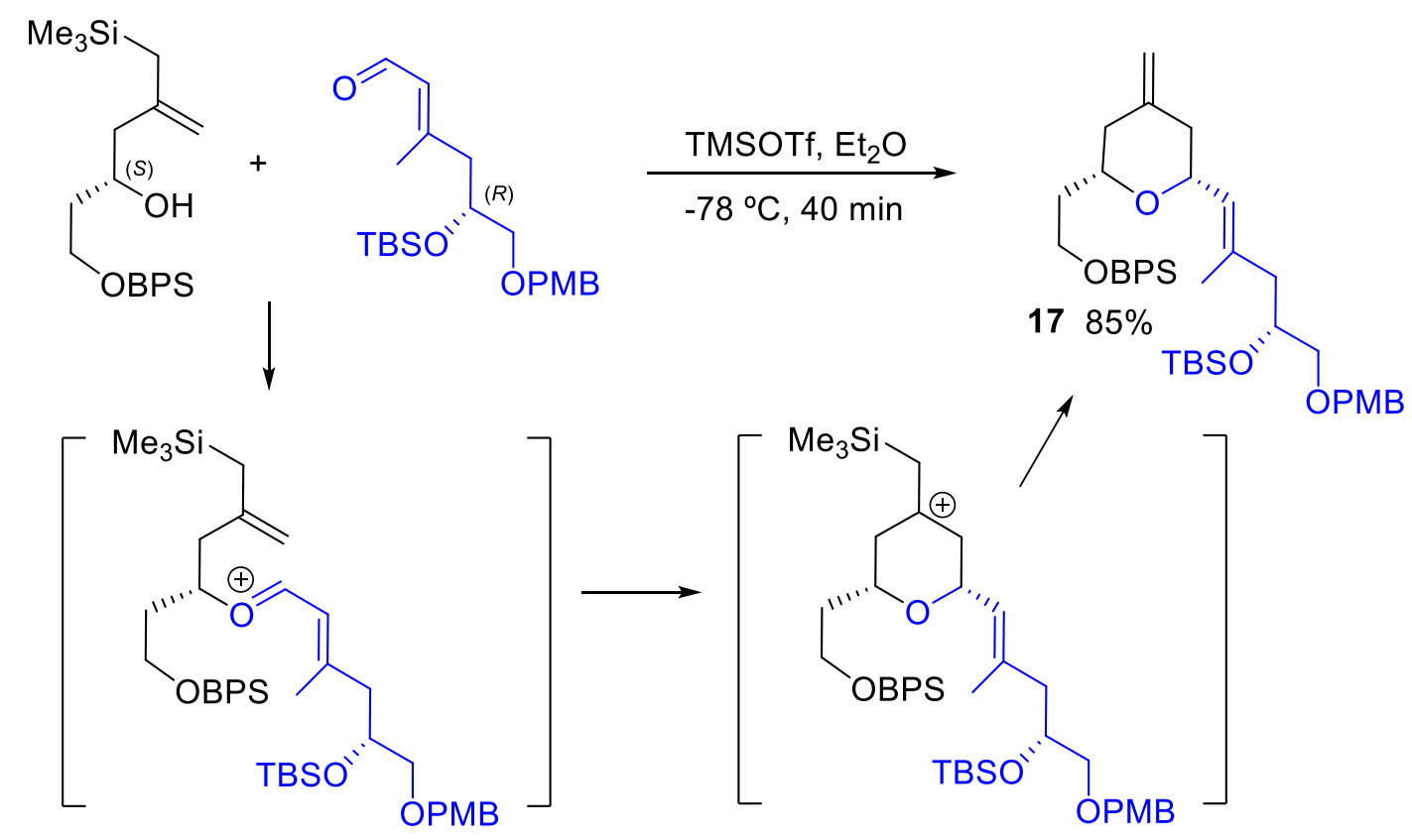

\section{Scheme 30}

Both strategies, Prins and silyl-Prins cyclization, have been mainly applied to the synthesis of sixmembered oxacycles and less frequently used for the construction of larger-ring heterocycles. Our research group has recently reported the synthesis of medium-sized oxa- and azacycles by silyl-Prins cyclization of allylsilyl alcohols.

\subsection{Synthesis of seven-membered oxacycles}

The synthesis of oxepanes has attracted growing attention in the international scientific community due to their interesting structure and wide occurrence in a variety of natural products. As already mentioned, examples of synthesis of seven-membered oxacycles by Prins or silyl-Prins cyclization are not so abundant. Within the few attempts reported to obtain this type of heterocycles by silyl-Prins cyclization, Suginome and Ito $^{36}$ have described an approach to oxepane rings by TMSOTf mediated silyl-Prins cyclization of enantiomerically enriched silylated alkenols and aldehydes (Scheme 11).

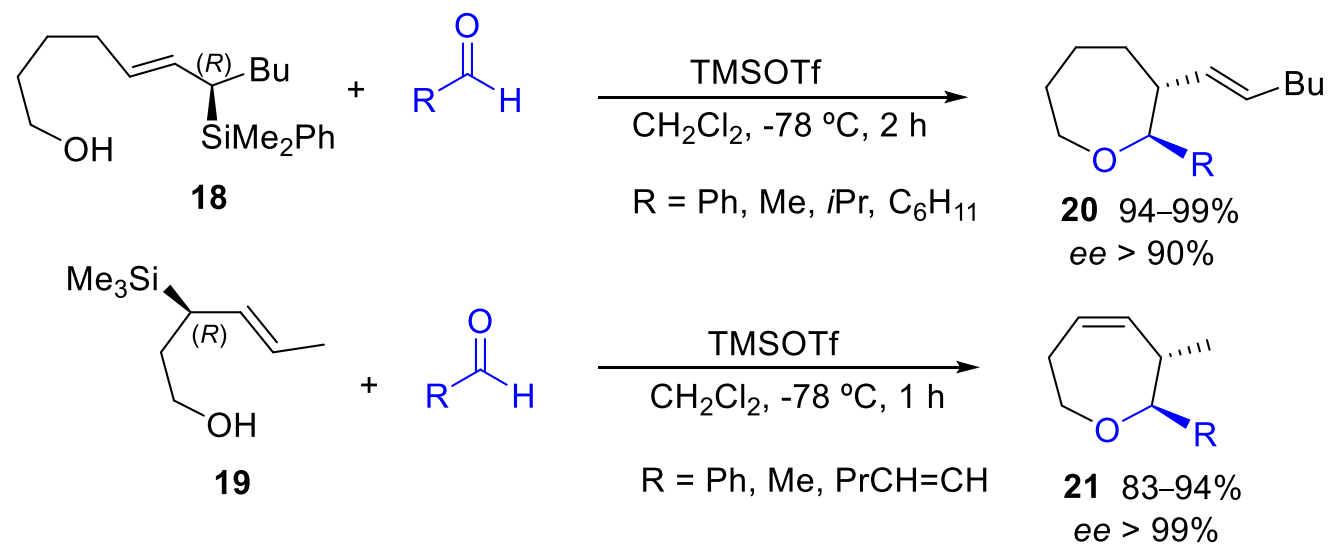

\section{Scheme 11}


We decided to develop a general approach to the synthesis of oxepanes by silyl-Prins cyclization of silylated bishomoallylic alcohols. The cyclization of these allylsilyl alcohols with aldehydes in the presence of TMSOTf (which was the most effective catalyst) proved to be high yielding for a wide variety of vinyl and aryl (both electron-rich and electron-deficient) aldehydes. Moreover, the reaction proceeded with excellent diastereoselectivity to afford the all-cis trisubstituted oxepane as a single stereoisomer 22 (Scheme 12). ${ }^{37}$

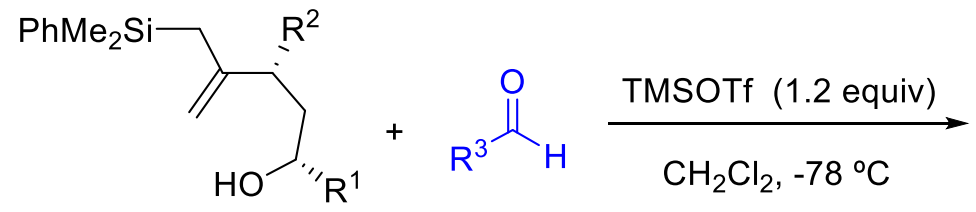

2

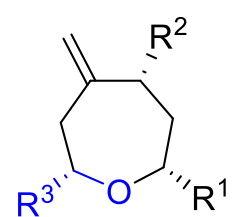

22

11 examples, $71-93 \%$

$d r \geqslant 95: 5$

$\mathrm{R}^{1}=\mathrm{Ph}, \mathrm{Me}$

$\mathrm{R}^{2}=\mathrm{Ph}$

$R^{3}=$ aryl, vinyl

\section{Scheme 12}

The high stereocontrol of this process can be explained through a mechanism involving both the formation of a preferred E-oxocarbenium ion and a chair-like transition state (V) in which the substituents adopt the most stable equatorial conformation (Scheme 13).
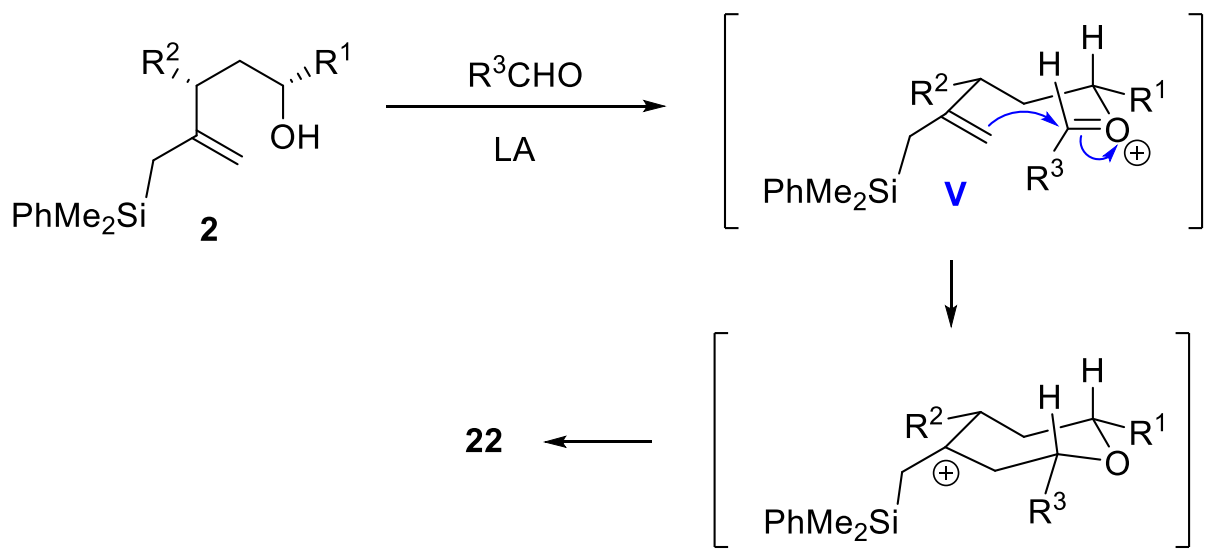

\section{Scheme 13}

We then determined to carry out a detailed study on the factors that affect the selectivity and the outcome of the process. To understand the influence of the configuration of the starting alcohol on the selectivity of the reaction, we initially chose allylsilyl alcohols with a trans-relationship between substituents $R^{1}$ and $R^{2}$. As can be seen in Scheme 14, the silyl-Prins cyclization of alcohols 3 again proceeds under mild conditions, providing a single diastereoisomeric oxepane $\mathbf{2 3}$ (Scheme 14). It should be noted that in this case two different transition states could be drawn in which either $R^{1}$ or $R^{2}$ are equatorial. The formation of a unique isomer bearing an equatorial $R^{1}$ group seems to indicate that the close proximity of this group to the reactive oxocarbenium ion accounts for this effect. These results are consistent with Houk's calculations ${ }^{38}$ 
which predict that the stereoselectivity associated with the attack of a nucleophile on an oxocarbenium ion is controlled by the adjacent stereogenic center.

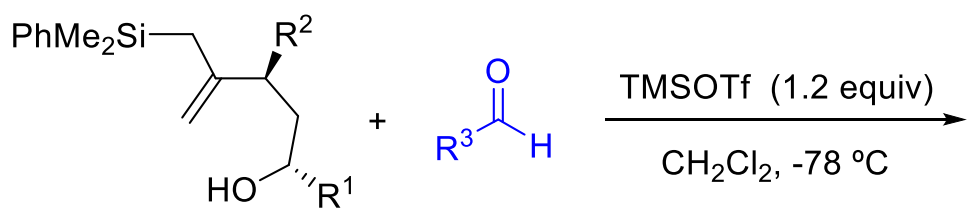

3<smiles>[R]C1CC(=C)C([R])CC([R])O1</smiles>

23

11 examples, $72-93 \%$

$d r \geqslant 95: 5$

$\mathrm{R}^{1}=\mathrm{Ph}, \mathrm{Me}$

$\mathrm{R}^{2}=\mathrm{Ph}$

$\mathrm{R}^{3}=$ aryl, vinyl, alkyl

\section{Scheme 14}

To further explore this hypothesis, we chose for this cyclization alcohols with $\mathrm{R}^{1}=\mathrm{H}$. As shown in Scheme 15 , silyl-Prins cyclization of these primary alcohols give oxepanes with consistent high yields, albeit with reduced stereoselectivity towards the cis-isomer. The lower stereocontrol observed in this case again confirms the required presence of a stereogenic center $\alpha$ to the oxocarbenium ion for the nucleophilic attack of the allylsilane to be selective. (Scheme 15)

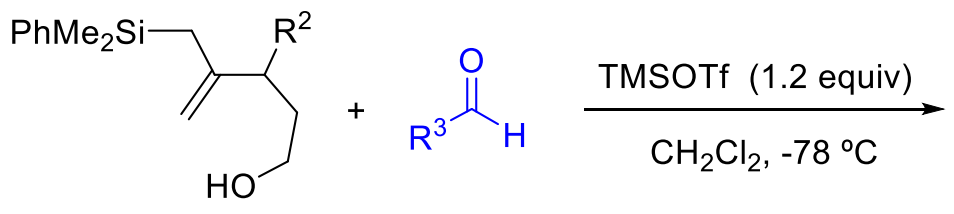

24

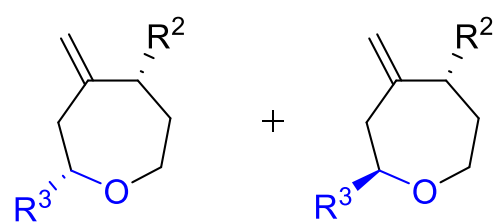

25
26

8 examples, $88-94 \%$

dr 25:26 from 75:25 to $91: 9$

$\mathrm{R}^{2}=\mathrm{Ph}$

$\mathrm{R}^{3}=$ aryl, vinyl, alkyl

\section{Scheme 15}

Continuing with the study of the effect of number and position of substituents on the starting silyl alkenol, we selected alcohols where $\mathrm{R}^{2}$ is hydrogen. To our surprise, and under the same conditions, the outcome of the process was completely different. In this case, the reaction mainly provided a new adduct, which was shown to be dioxaspirodecane 28. ${ }^{39}$ The reaction is general for a wide variety of aldehydes (aryl, vinyl and alkyl) although in some examples small amounts of the corresponding oxepane derivative $\mathbf{2 9}$ are obtained together with the major spiro-compound (Scheme 16). 


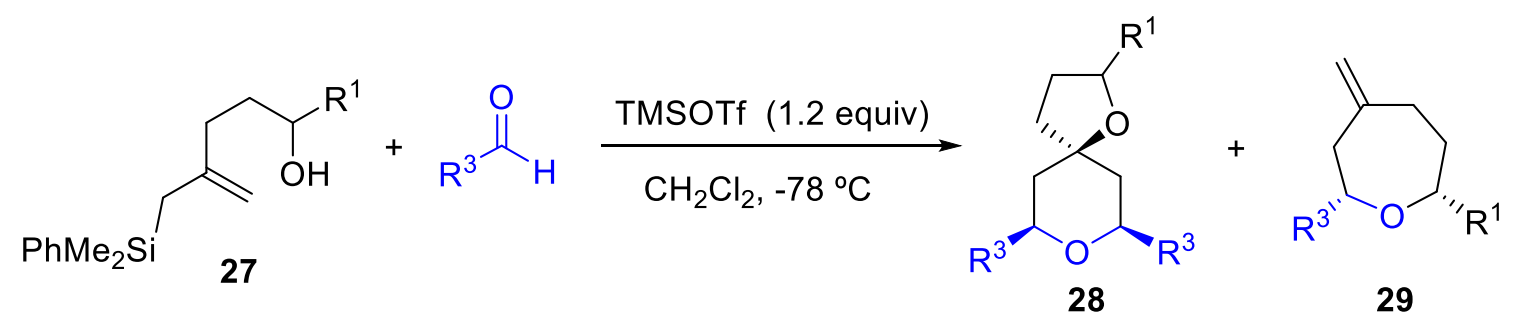

15 examples, $63-89 \%$

Ratio $28: 29$ up to $95: 5$

dr $\mathbf{2 8}>95: 5$

$\mathrm{R}^{1}=\mathrm{Me}, \mathrm{H}$

$\mathrm{R}^{3}=$ aryl, vinyl, alkyl

\section{Scheme 16}

The proposed mechanism for this process is a domino Sakurai-Prins cyclization which involves an initial Sakurai allylation. In the presence of another molecule of aldehyde, the intermediate homoallylic alkoxide undergoes Prins cyclization providing a tetrahydropyranyl cation which is intramolecularly captured by the hydroxyl group present in the molecule (Scheme 17).

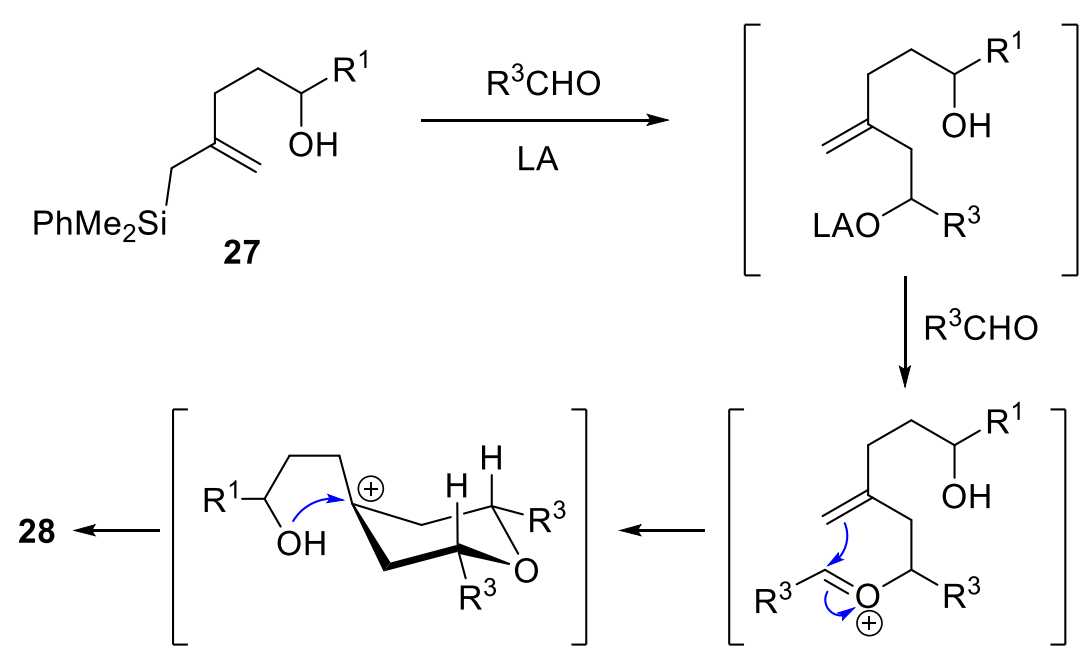

\section{Scheme 17}

It should be noted that in this three component reaction, three new stereogenic centers have been created with total stereocontrol (a single stereoisomer is observed). The syn relationship between substituents at $\mathrm{C} 2$ and $\mathrm{C} 6$ is easily rationalized through a preferred chair-like transition state in which both groups adopt the more stable equatorial conformation. However, the configuration of the spiro carbon indicates a preferred equatorial trapping of the tetrahydropyranyl cation, a result that disagrees with Alder's calculation ${ }^{40}$ which predicts the axial attack of a nucleophile at a tertiary cyclic cation, obtained by Prins cyclization, as the most favourable pathway. The only difference between our experimental results and Alder's calculations is that in our case the trapping is intramolecular while Alder's theoretical calculations were done for an intermolecular nucleophilic attack. To gain more insight into these results, we performed theoretical studies, calculating the minimum energy of the intermediate cyclic cation and the activation energies of the two possible pathways: the axial and the equatorial nucleophilic attack. As shown in Scheme 18, the activation 
energies of pathways $a$ and $b$ are rather different, which explains the favourable formation of the spirane corresponding to the axial attack under kinetic conditions.

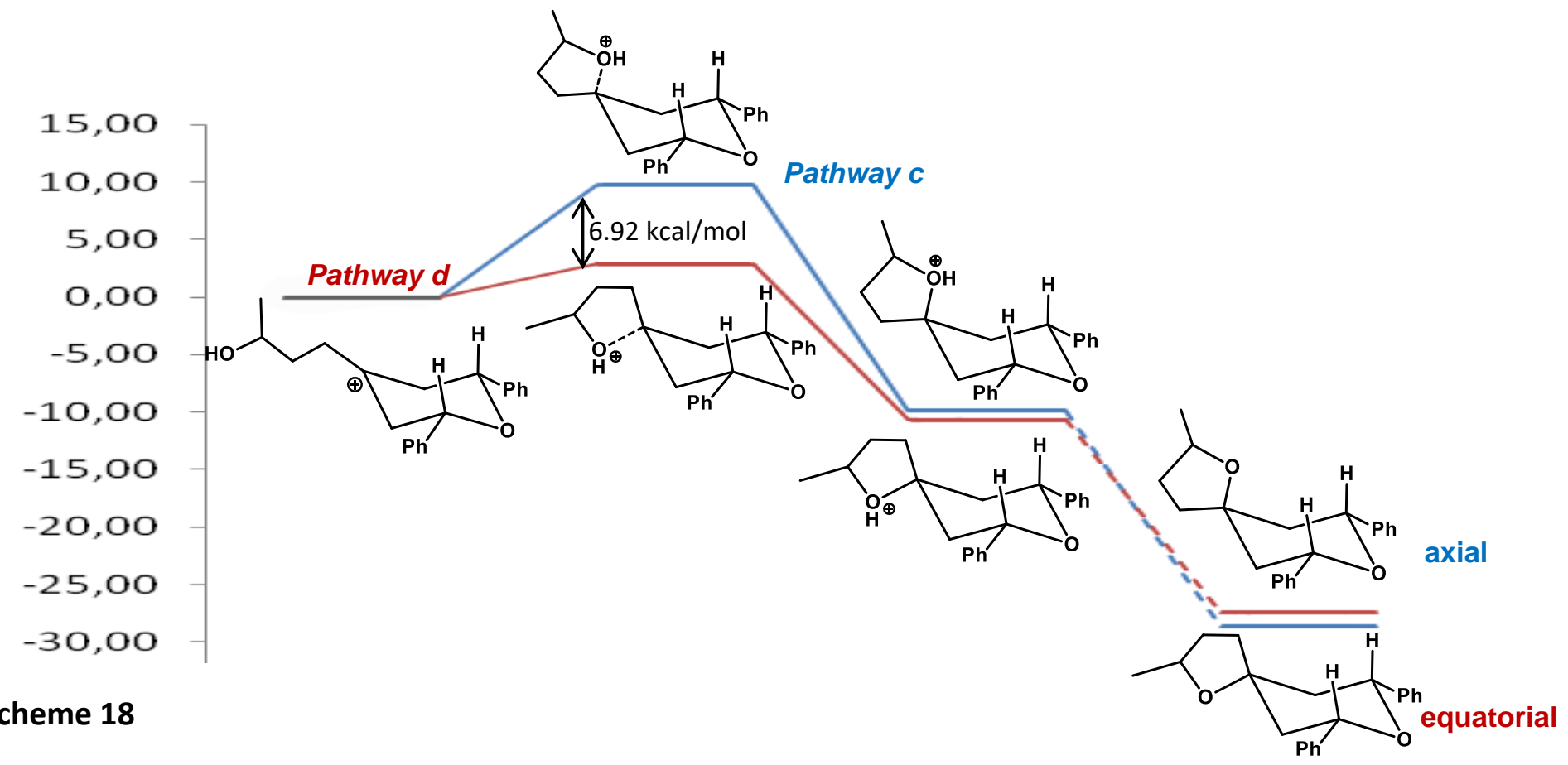

\subsection{Synthesis of eight-membered oxacycles}

An even more challenging goal is the synthesis of eight-membered-ring ethers by Prins cyclization. Within the scarce precedents in this field, Overman ${ }^{41}$ was the first to describe the preparation of oxocenes by Prins cyclization. The reaction of 5-hexenyl acetals, mediated by Lewis acids, is highly stereoselective (a single diastereoisomer is formed) although yields tend to be low unless the vinylic $\mathrm{R}$ substituent is a phenylthio group (Scheme 19).
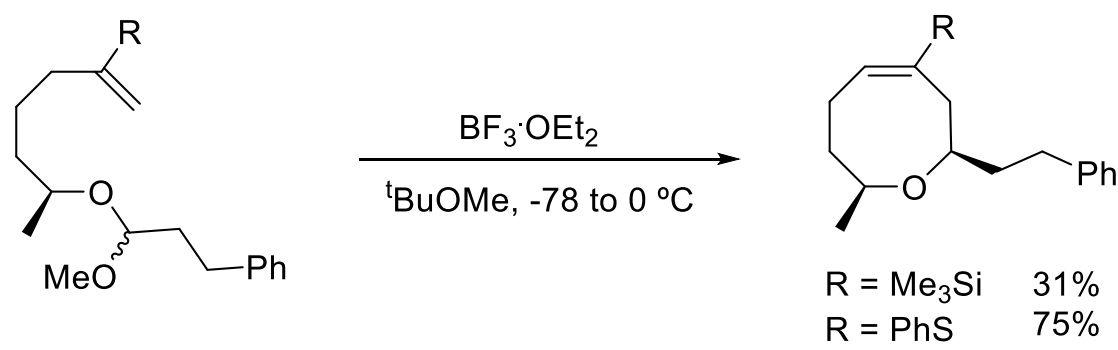

\section{Scheme 19}

Our research group has recently reported a general methodology for the synthesis of polysubstituted oxocanes by silyl-Prins cyclization of silylated tris-homoallylic alcohols $\mathbf{3 0}$ and aldehydes. ${ }^{42}$ The reaction is general and high-yielding for several types of aldehydes, including arylic (both electron-rich and electrondeficient) and vinylic aldehydes. Moreover, a single cis-2,5-disubstituted oxocane $\mathbf{3 1}$ is obtained in every case, which seems to indicate a preferred transition state with these two substituents in pseudo-equatorial conformation. It should be noted that the initial silylated alcohol bears a gem-dimethyl group, ${ }^{43}$ which we think determines the success of this cyclization (the so-called Thorpe-Ingold effect) (Scheme 20). 


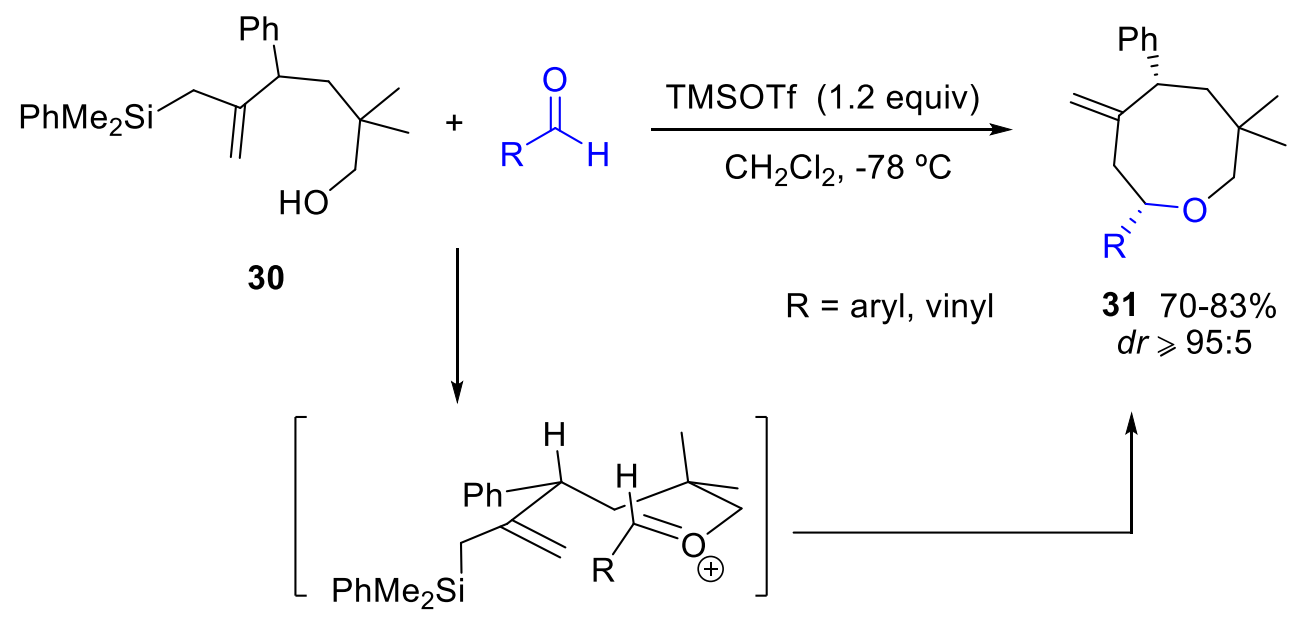

\section{Scheme 20}

In order to examine the effect of the allylic substituent on the reaction, we next chose a tris-homoallylic alcohol lacking this type of substituent. As can be seen in Scheme 21, the reaction again follows a completely different pathway, now providing dioxaspiroundecanes through a domino Sakurai-Prins cyclization.

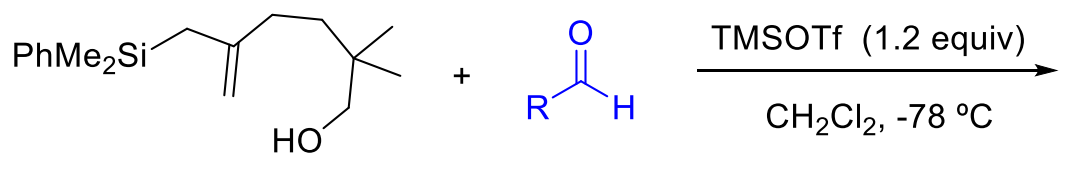

32

$$
\begin{gathered}
\mathrm{R}=\text { aryl, vinyl } \quad 33 \quad 49-69 \% \\
d r \geqslant 95: 5
\end{gathered}
$$

\section{Scheme 21}

Thus, two types of reaction pathway are observed in the acid-mediated cyclization of bis- and trishomoallylic alcohols, depending on the substitution of the alcohol. Presumably, steric effects account for this substitution pattern. We envisioned that, apart from steric effects, the nature of the Lewis acid may have a great influence. Since the previous reactions were done using TMSOTf as a Lewis acid, we decided to check the chemical behaviour of the reaction in the presence of other Lewis acids, from which $\mathrm{BF}_{3} \cdot \mathrm{OEt}_{2}$ gave interesting results. As can be seen in Scheme 22, the reaction of tris-homoallylic alcohols, lacking an allylic substituent, with aldehydes in the presence of $\mathrm{BF}_{3} \cdot \mathrm{OEt}_{2}$ selectively provides oxocanyl derivatives (none of the corresponding dioxaspiroundecane is observed). Although this catalyst effect remains to be rationalized, the most favourable pathway will be determined by the ease with which the Sakurai reaction (the initial step of the domino process leading to dioxaspiroundecanes) or the formation of the oxocarbenium ion (the initial step of the direct silyl-Prins cyclization) take place. 


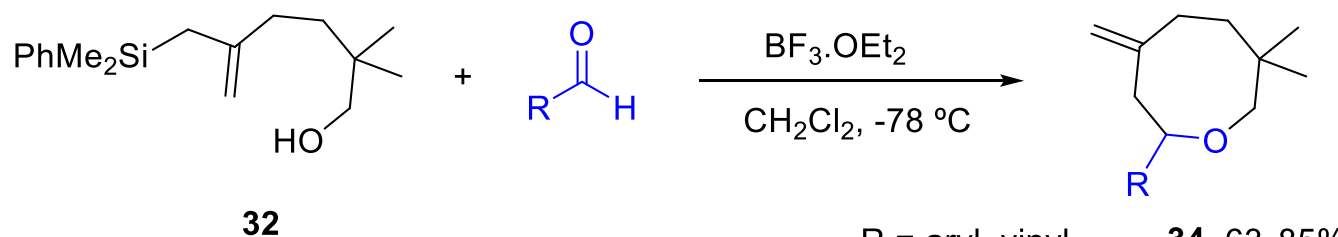

$$
\mathrm{R}=\text { aryl, vinyl } \quad 3463-85 \%
$$

\section{Scheme 22}

Contemporary with our work, Ghosh et al. ${ }^{44}$ have described an approach to the synthesis of oxocenes through a two component Prins cyclization. Under optimized conditions (using TMSOTf in THF) they were able to obtain 2,4,8-trisubstituted oxocenes 36 with excellent stereoselectivity to form the 2,8-cis diastereoisomer, although in low yields unless $\mathrm{R}^{2}$ is a nitro group (Scheme 23 ).

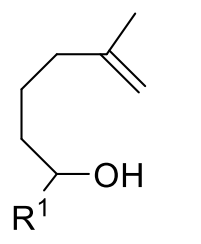

35<smiles>[R]c1cccc(C=O)c1</smiles>

R

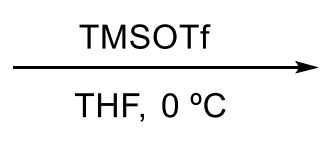

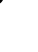

\section{Scheme 23}

\section{Synthesis of Azacycles by Silyl-Prins Cyclization}

The synthesis of nitrogen heterocycles by Prins cyclization is called aza-Prins cyclization and is significantly less developed than the standard methodology. The silylated version (the silyl-aza-Prins cyclization) has shown various advantages such as allowing the use of an array of protected amines or providing more selective reactions. Two types of protocols have been mainly used in this reaction: the two component cyclization, which involves the acid-mediated reaction of a homoallylic amine with an aldehyde to give an intermediate iminium cation. Subsequent 6 -endo cyclization will provide a piperidinium cation, that is finally trapped by a nucleophile present in the media. This approach has been used by Remuson ${ }^{45}$ in the synthesis of natural alkaloid (+)-isosolenopsin A. The good diastereoselectivity observed towards the final 2,6-cis piperidine $\mathbf{3 7}$ was explained through the formation of a preferred $E$-iminium ion intermediate and a chair like transition state of minimum energy. However, an aza-Cope rearrangement (side reaction) seems to be responsible for the observed racemization process (Scheme 24).

The second methodology employed in this cyclization involves the use of a single precursor, which in the presence of the acid catalyst is transformed into the iminium ion required for the cyclization. Speckamp's group ${ }^{46}$ has explored this type of one-component protocol in the synthesis of 2,3-disubstituted piperidines 38. In this approach, treatment of an $\alpha$-ethoxy amide with formic acid generates the iminium ion intermediate, which is then captured by the allylsilane (Scheme 25). 
<smiles>C=C(C[Si]C(C)C)C[C+](C)N</smiles>

ee $82 \%$

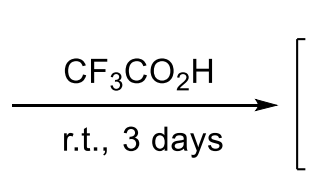

r.t., 3 days
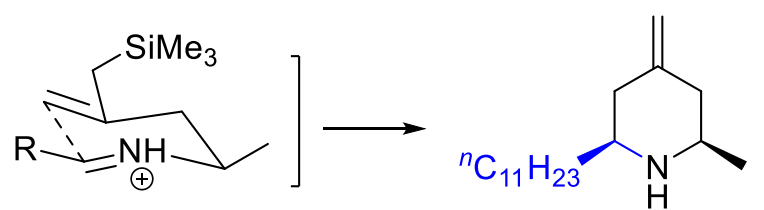

$3770 \%$ de $82 \%$, ee $38 \%$

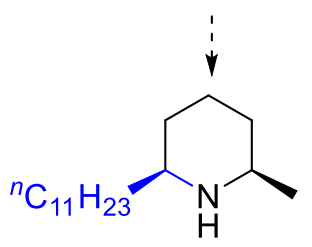

(+)-isosolenopsin A

\section{Scheme 24}

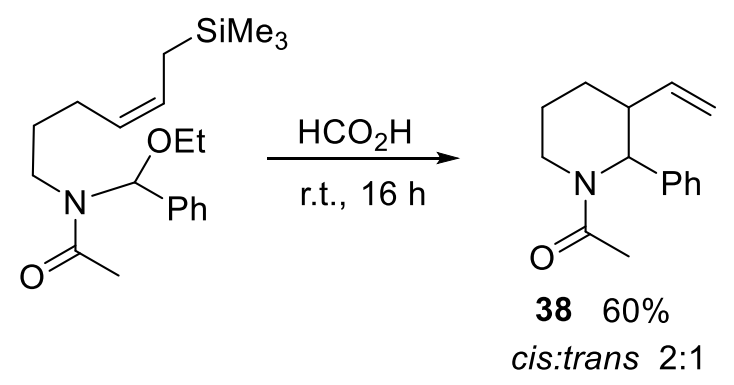

\section{Scheme 25}

As already mentioned, both Prins and silyl-Prins cyclization have been mainly applied to the synthesis of five- or six-membered azacycles. In this context, our research group decided to study an approach to the preparation of seven-membered azacycles by silyl-Prins cyclization. ${ }^{47}$ This type of compound occurs in both natural and synthetic compounds with biological activity, such as the natural product ophiocordin ${ }^{48}$ (an antifungal antibiotic isolated from submerged cultures of Cordyceps ophioglossoides) or synthetic trihydroxyazepanes, which have demonstrated good glycosidase inhibitory potency. ${ }^{49}$

Our approach to these interesting structures started with the synthesis of the initial silylated bishomoallylic amines by silylcupration of allene and capture of the intermediate with enones, followed by reductive amination. Within the numerous Lewis acids tested for this cyclization, $\mathrm{InCl}_{3}$ was found to be the only effective catalyst for the process. ${ }^{50}$ The reaction is general and high yielding for various types of aldehydes (both $\alpha, \beta$-unsaturated and aromatic aldehydes). Moreover, 2,6-trans-disubstituted azepanes 40 were always the predominant stereoisomers, with selectivities ranging from moderate (80:20) to excellent (>95:5). (Scheme 26) 


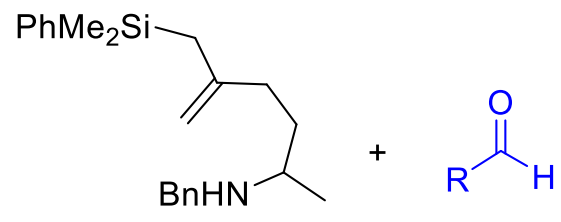

39

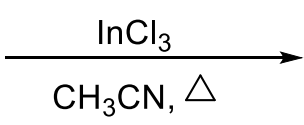

$\mathrm{R}^{\prime \prime}$

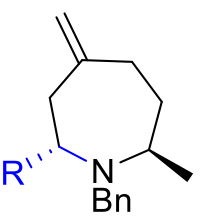

$4075-82 \%$

$$
\begin{array}{lr}
\mathrm{R}=(E)^{-}{ }^{-} \mathrm{BuCH}=\mathrm{CPh} & >95: 5 \text { trans:cis } \\
\mathrm{R}=4-\mathrm{MeC}_{6} \mathrm{H}_{4} & 88: 12 \text { trans:cis } \\
\mathrm{R}=4-\mathrm{ClC}_{6} \mathrm{H}_{4} & 80: 20 \text { trans:cis }
\end{array}
$$

\section{Scheme 26}

The stereoselectivity of this reaction seems to be controlled by the preferential formation of a more stable Z-iminium ion which undergoes 7-endo cyclization through a chair-like transition state with the substituents in the minimum energy conformation (Scheme 27).

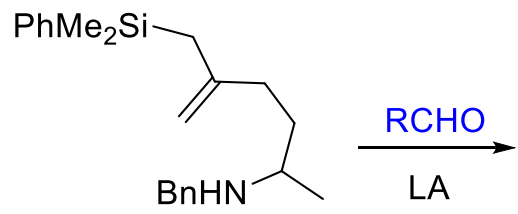

39

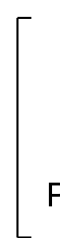

$\mathrm{PhMe}_{2} \mathrm{Si}$

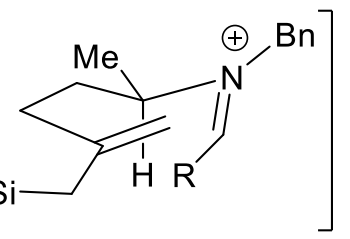

Z-iminium ion

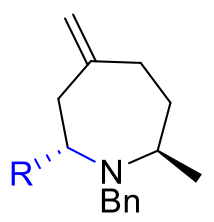

40

\section{Scheme 27}

\section{Conclusions}

This account summarizes our recent results concerning the synthesis of differently sized oxa- and azacycles starting from organosilanes. Two different methodologies have been used to prepare these scaffolds: the acidmediated cyclization of silylated alkenyl alcohols and the silyl-Prins (or silyl-aza-Prins) cyclization of silyl alkenols (or silyl alkenamines). The influence of structural factors in the stereochemistry of these processes has been studied and mechanistic rationales have been proposed.

\section{Acknowledgements}

We thank the "Junta de Castilla y León" (VA294P18) for financial support. C.D.-P. acknowledges a predoctoral Grant (Q4718001C), funded by the European Social Fund and the "Junta de Castilla y León".

\section{References}

1. Yang, P.; Li, P.-F.; Qu, J.; Tang, L.-F. Org. Lett. 2012, 14, 3932-3935. https://doi.org/10.1021/ol3016836 
2. Kobayashi, J. J. Antibiot. 2008, 61, 271-284.

3. Linder, T.; Liu, R.; Atanasov, A. G.; Li, Y.; Geyrhofer, S.; Schwaiger, S.; Stuppner, H.; Schnürch, M.; Dirsch, V. M.; Mihovilovic, M. D. Chem. Sci. 2019, 10, 5815-5820.

https://doi.org/10.1039/C9SC00446G

4. Cardellina, J. H.; Moore, R. E.; Arnold, E. V.; Clardy, J. J. Org. Chem. 1979, 44, 4039-4042.

5. Yanai, M.; Ohta, S.; Ohta, E.; Ikegami, S. Tetrahedron 1998, 54, 15607-15612.

https://doi.org/10.1016/S0040-4020(98)01013-8

6. Wyche, T. P.; Alvarenga, R. F. R.; Piotrowski, J. S.; Duster, M. N.; Warrack, S. R.; Cornilescu, G.; De Wolfe, T. J.; Hou, Y.; Braun, D. R.; Ellis, G. A.; Simpkins, S. W.; Nelson, J.; Myers, C. L.; Steele, J.; Mori, H.; Safdar, N.; Markley, J. L.; Rajski, S. R.; Bugni, T. S. ACS Chem. Biol. 2017, 12, 2287-2295.

https://doi.org/10.1021/acschembio.7b00388

7. Barbero, H.; Díez-Poza, C.; Barbero, A. Mar. Drugs 2017, 15, 361.

https://doi.org/10.3390/md15110361

8. Cimino, G.; Madaio, A.; Trivellone, E.; Uriz, M. J. Nat. Prod. 1994, 57, 784-790.

9. Pettit, G. R.; Herald, C. L.; Allen, M. S.; Von Dreele, R. B.; Vanell, L. D.; Kao, J. P. Y.; Blake, W. J. Am. Chem. Soc. 1977, 99, 262-263.

10. König, G. M.; Wright, A. D.; Sticher, O.; Angerhofer, C. K.; Pezzuto, J. M. Planta Med. 1994, 60, 532-537. https://doi.org/DOI:10.1055/s-2006-959565

11. Daoust, J.; Chen, M.; Wang, M.; Williams, D. E.; Chavez, M. A. G.; Wang, Y. A.; Merchant, C. E.; Fontana, A.; Kieffer, T. J.; Andersen, R. J. J. Org. Chem. 2013, 78, 8267-8273.

https://doi.org/10.1021/jo4014589

12. Kulanthaivel, P.; Hallock, Y. F.; Boros, C.; Hamilton, S. M.; Janzen, W. P.; Ballas, L. M.; Loomis, C. R.; Jiang, J. B.; Katz, B. J. Am. Chem. Soc. 1993, 115, 6452-6453.

https://doi.org/10.1021/ja00067a087

13. Kneifel, H.; Konig, W. A.; Loeffler, W.; Müller, R. Arch. Microbiol. 1977, 113, 121-130.

14. Barbero, A.; Pulido, F.J. Synthesis 2004, 779-785.

https://doi.org/10.1055/s-2007-965917

15. Barbero, A.; Blanco, Y.; Pulido, F.J. J. Org. Chem. 2005, 70, 6876-6883.

https://doi.org/10.1021/jo0509814

16. Barbero, A.; Blanco, Y.; Pulido, F.J. Chem. Commun. 2001, 1606-1607. https://doi.org/10.1039/B103387P

17. Andrey, O.; Glanzmann, C.; Landais, Y.; Parra-Rapado, L. Tetrahedron 1997, 53, 2835-2854. https://doi.org/10.1016/S0040-4020(97)00003-3

18. Freeman, F.; Robarge, K. D. Tetrahedron Lett. 1985, 26, 1943-1946.

https://doi.org/10.1016/S0040-4039(00)98347-3

19. Z. M.; Kostic, M. D.; Divac, V. M. Curr. Org. Chem. 2016, 20, 777-797.

20. Linares-Palomino, P. J.; Salido, S. A.; Altarejos, J. N.; Sánchez, A. Tetrahedron Lett. 2003, 44, 6651-6655. https://doi.org/10.1016/S0040-4039(03)01635-6

21. Coulombel, L.; Duñach, E. Green Chem. 2004, 6, 499-501. https://doi.org/10.1039/B408760G

22. Coulombel, L.; Favier, I.; Duñach, E. Chem. Commun. 2005, 2286-2288. https://doi.org/10.1039/B501601K

23. Dzudza, A.; Marks, T. J. Chem. Eur. J. 2010, 16, 3403-3422. https://doi.org/10.1002/chem.200902269 
24. Rosenfeld, D. C.; Shekhar, S.; Takemiya, A.; Utsunomiya, M.; Hartwig, J. F. Org. Lett. 2006, 8, 4179-4182. https://doi.org/10.1021/ol061174+

25. Barbero, A.; Castreño, P.; Pulido, F. J. J. Am. Chem. Soc. 2005, 127, 8022-8023. https://doi.org/10.1021/ja051967b

26. Pulido, F. J.; Barbero, A.; Val, P.; Diez, A.; González-Ortega, A. Eur. J. Org. Chem. 2012, 5350-5356. https://doi.org/10.1002/ejoc.201200666

27. Miura, K.; Hondo, T.; Nakagawa, T.; Takahashi, T.; Hosomi, A. J. Am. Chem. Soc. 2000, 122, $11348-11357$. https://doi.org/10.1021/ja002496q

28. Miura, K.; Hosomi, A. Synlett 2003, 143-155.

https://doi.org/10.1055/s-2003-36776

29. Barbero, A.; Barbero, H.; González-Ortega, A.; Pulido, F. J.; Val, P.; Diez-Varga, A.; Morán, J. R. RSC Advances 2015, 5, 49541-49551.

https://doi.org/10.1039/C5RA06640A

30. Díez-Poza, C.; Val, P.; Pulido, F. J.; Barbero, A. Mar. Drugs 2018, 16, 421. https://doi.org/10.3390/md16110421

31. Pastor, I. M.; Yus, M. Curr. Org. Chem. 2007, 11, 925-957. https://doi.org/10.2174/138527207781024067

32. Han, X.; Peh, G.; Floreancig, P. E. Eur. J. Org. Chem. 2013, 1193-1208. https://doi.org/10.1002/ejoc.201201557

33. Olier, C.; Kaafarani, M.; Gastaldi, S.; Bertrand, M. P. Tetrahedron 2010, 66, 413-445. https://doi.org/DOI:10.1016/i.tet.2009.10.069

34. Díez-Poza, C.; Barbero, A. Eur. J. Org. Chem. 2017, 4651-4665.

https://doi.org/10.1002/ejoc.201700644

35. Sánchez, C. C.; Keck, G. E. Org. Lett. 2005, 7, 3053-3056.

https://doi.org/10.1021/ol051040g

36. Suginome, M.; Iwanami, T.; Ito, Y. Chem. Commun. 1999, 2537-2538.

https://doi.org/10.1039/A908603J

37. Diez-Varga, A.; Barbero, H.; Pulido, F. J.; González-Ortega, A.; Barbero, A. Chem. Eur. J. 2014, 20, 1411214119.

https://doi.org/10.1002/chem.201403421

38. Broeker, J. L.; Hoffmann, R. W.; Houk, K. N. J. Am. Chem. Soc. 1991, 113, 5006-5017.

https://doi.org/10.1021/ja00013a041

39. Barbero, A.; Diez-Varga, A.; Pulido, F. J. Org. Lett. 2013, 15, 5234-5237.

https://doi.org/10.1021/ol402425u

40. Alder, R. W.; Harvey, J. N.; Oakley, M. T. J. Am. Chem. Soc. 2002, 124, 49604961. https://doi.org/10.1021/ja025902+

41. Bratz, M.; Bullock, W. H.; Overman, L. E. Takemoto, T. J. Am. Chem. Soc. 1995, 117, 5958-5966. https://doi.org/10.1021/ja00127a008

42. Barbero, A.; Diez-Varga, A.; Herrero, M.; Pulido, F. J. J. Org. Chem. 2016, 81, 2704-2712. https://doi.org/10.1021/acs.joc.5b02260

43. Jung, M. E.; Piizzi, G. Chem. Rev. 2005, 105, 1735-1766. https://doi.org/10.1021/cr940337h

44. Ghosh, A. K.; Tomaine, A. J.; Cantwell, K. E. Org. Lett. 2016, 18, 396-399. https://doi.org/10.1021/acs.orglett.5b03411 
45. Monfray, J.; Gelas-Mialhe, Y.; Gramain, J.-C.; Remuson, R. Tetrahedron: Asymmetry 2005, 16, $1025-1034$. https://doi.org/10.1016/j.tetasy.2005.01.018

46. Hiemstra, H.; Fortgens, H. P.; Speckamp, W. N. Tetrahedron Lett. 1985, 26, 3155-3158. https://doi.org/10.1016/S0040-4039(00)98644-1

47. Barbero, A.; Diez-Varga, A.; Pulido, F. J.; Gonzalez-Ortega, A. Org. Lett. 2016, 18, 1972-1975. https://doi.org/10.1021/acs.orglett.6b00538

48. Kneifel H.; König W. A.; Loeffler W.; Müller R. Arch Microbiol. 1977, 113, 121-130.

49. Shih, T.-L.; Yang, R.-Y.; Li, S.-T.; Chiang, C.-F.; Lin C.-H. J. Org. Chem. 2007, 72, 4258-4261. https://doi.org/10.1021/jo070058x

50. Dobbs, A. P.; Guesné, S. J. J.; Martinović, S.; Coles, S. J.; Hursthouse, M. B. J. Org. Chem. 2003, 68, 78807883.

https://doi.org/10.1021/jo034981k

This paper is an open access article distributed under the terms of the Creative Commons Attribution (CC BY) license (http://creativecommons.org/licenses/by/4.0/)

\section{Authors' Biographies}

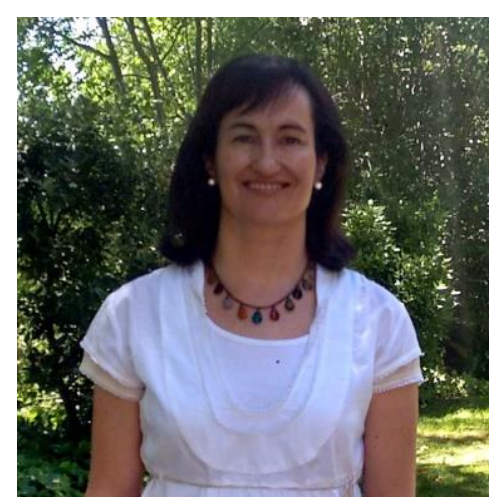

Asunción Barbero was born in Burgos (Spain) and studied Chemistry at the University of Valladolid. Later, she undertook her PhD studies at the same University (Prof. Pulido), being recognized with the Doctorate Extraordinary Award. She then held a Marie Curie Postdoctoral Fellowship working for two years at the University of Cambridge under the supervision of Prof. Ian Fleming in the study of stereocontrol in organic synthesis using silicon chemistry. After returning to Valladolid, she was first appointed as Assistant Professor and then promoted to Associate Professor (2001) and to Full Professor (2019). She has co-authored around 60 high impact scientific publications and has delivered several invited and plenary lectures in international conferences. Her current interests include the use of organosilanes in the synthesis of carbo- and heterocycles. 


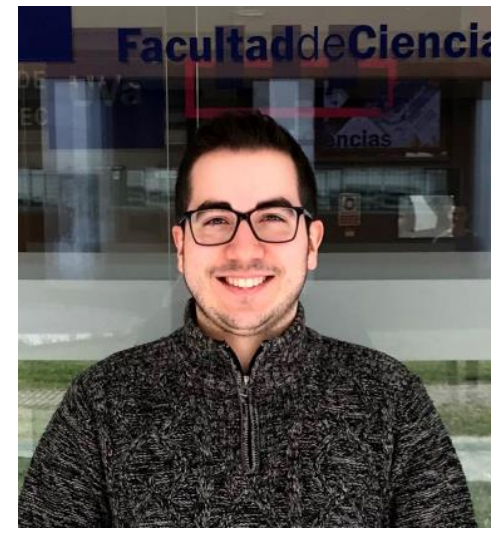

Carlos Díez-Poza received his B.Sc. in Chemistry in 2015 and his Master's degree in 2016 from the University of Valladolid. Currently he is a Ph.D. student in the same University under the supervision of Prof. Asunción Barbero. He has spent two short research stays with Prof. Opatz (University of Mainz) and Prof. D'Hooghe (University of Ghent). He is co-author of various papers, reviews and book chapters. His research interests include the synthesis of heterocycles by silyl-Prins cyclizations.

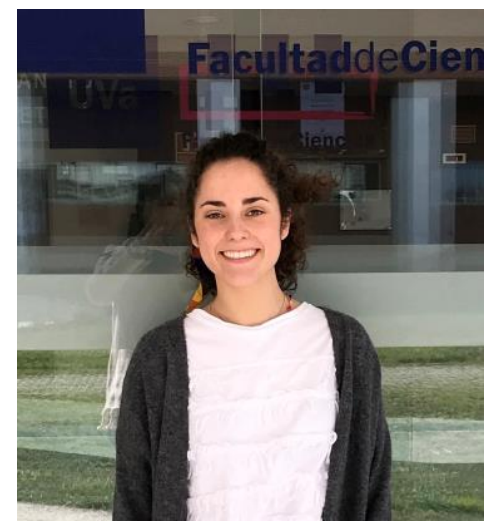

Laura Fernández-Peña obtained her B.Sc. in Chemistry in 2018 from the University of Valladolid and her Master's degree in 2019 from the Autonomous University of Madrid. At present she is a Ph.D. student at the University of Valladolid under the supervision of Prof. Asunción Barbero working in the use of organosilanes for the synthesis of various types of heterocycles.

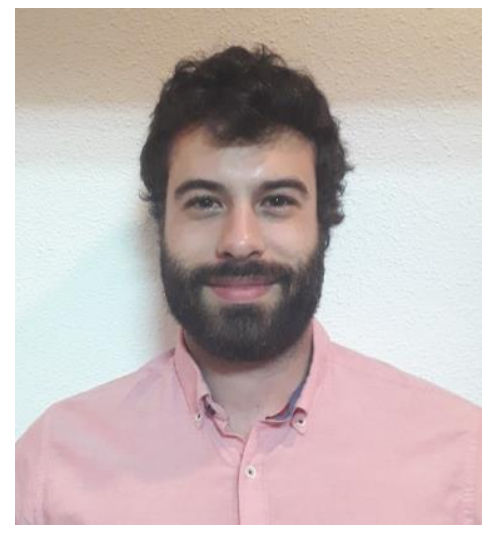

Alberto Cherubin holds a Bachelor's degree in chemistry from the University of Genova and a Master's degree in Chemical Science from the same University. In 2018 he moved to the University of Valladolid, starting a 
project aiming the preparation of oxacycles from alkenylsilanes under the supervision of Prof. Barbero. Currently he is a research technician at the University of Valladolid.

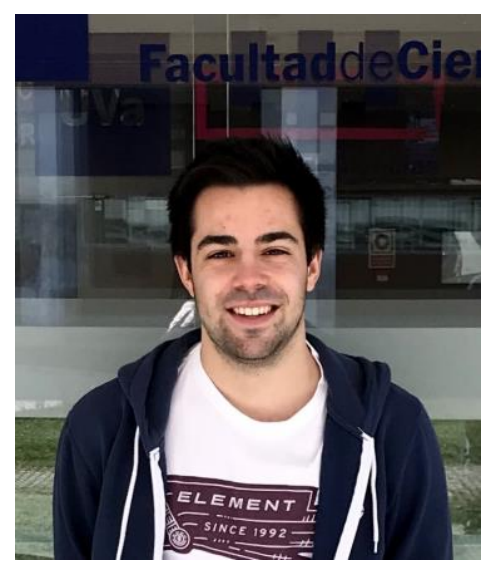

Juan Lión-Villar completed his undergraduate studies in chemistry and his master's degree at the University of Valladolid. He then moved to the Higher Council for Scientific Research (CSIC) in Madrid where he is working as research technician. 